\title{
Pengaruh Sudut Jumping Terhadap Aliran Air
}

\author{
Dimas Aji Putro $\mathbf{M}^{1}$, \& Mugisidi ${ }^{2}$ \\ ${ }^{1,2}$ Progam Studi Teknik Mesin Fakultas Teknik Uhamka \\ Jl. Tanah Merdeka No 6, Jakarta Timur - Indonesia Telp: (021) 87782739 \\ E-mail: dimasajiputraa57@gmail.com
}

\begin{abstract}
Abstrak - Penelitian ini bertujuan untuk melihat pengaruh sudut jumping terhadap aliran air dengan cara memvisualisasikan aliran air.Visualisasi dilakukan dengan metode menambahkan zat berwarna terhadap aliran air yang melewati talang air dengan dua aliran kecepatan yang berbeda dengan menggunakan dua perbandingan sudut jumping yaitu $45^{\circ}$ dan $90^{\circ}$. alat yang digunakan untuk metode memvisualisasikan yaitu menggunakan bantuan pompa air dan talang air serta pipa PVC untuk membentuk rekayasa aliran air. Hasil percobaan dengan nilai $R e=46650$ dan $R e=57416$ menunjukan bahwa pergerakan air ketika melewati sudut jumping $45^{\circ}$ derajat air bergerak laminar dan sudut jumping $90^{\circ}$ air bergerak turbulen karna bentuk sudut jumping $90^{\circ}$ menghambat pergerakan air.
\end{abstract}

Kata Kunci: Visualisasi, Sudut Loncat, Aliran Turbulen

\begin{abstract}
This study aims to see the effect of the jumping angle on water flow by visualizing the flow of water. Visualization is done by adding a colored substance to the water flow that passes through the gutter with two different flow velocities using two jumping angle comparisons, namely $45^{\circ}$ and $90^{\circ}$. The tools used for the visualizing method are using the help of a water pump and gutters and PVC pipes to form water flow engineering. The results of the experiment with Re values of 46650 and 57416 show that the movement of water when passing a jumping angle of $45^{\circ}$ the water moves laminar and the jumping angle of $90^{\circ}$ the water moves turbulently because the shape of the jumping angle of $90^{\circ}$ inhibits the movement of water.
\end{abstract}

Keyword: Visualization, Jumping Angle, Turbulent Flow

\section{PENDAHULUAN}

Energi air adalah energi yang dimanfaatkan oleh manusia secara luas untuk pembangkit listrik, sebagai listrik tenaga air maupun mikrohidro [1]. Potensi air sebagai sumber energi yang sangat penting bagi kebutuhan manusia di bumi dimana peningkatan kebutuhan disebabkan oleh kegiatan manusia yang semakin banyak dan pertumbuhan populasi manusia yang semakin lama terus meningkat secara signifikan khususnya di Indonesia. Hampir seluruh negara di dunia termasuk Indonesia saat ini sudah mulai merasakan dampak dari perubahan iklim global tersebut. Perubahan iklim global berpengaruh menyebabkan perubahan pola curah hujan. Namun bukan hanya tebal hujan yang berubah, intensitas, durasi dan sebaran hujan pun berubah.

Sering kita jumpai fenomena bentuk dasar sungai dalam morfologi sungai. Bentuk dasar ini terjadi disebabkan oleh aliran (flow induced) dan pengaruh kekasaran dasar (roughness). Saluran buatan dapat Dipresentasikan pada Tanggal 28 November 2020 Copyright @ 2020 FT - UHAMKA. - All rights reserved dikatagorikan sebagai saluran dengan konteks pemanfaatnya seperti, saluran drainase, saluran irigasi, saluran untuk pembangkit listrik tenaga air dan saluran untuk industri dan sebagainya termasuk model saluran yang dibuat di laboratorium untuk keperluan penelitian.

Energi potensial gravitasi adalah transformasi dari energi mekanik aliran air yang dimanfaatkan untuk menggerakkan turbin atau kincir. Pada dasarnya, turbin digunakan untuk membangkitkan energi listrik, sedangkan kincir untuk pemanfaatan energi mekanik secara langsung, kemudian dari energi mekanik tersebut dikonversi menjadi energi listrik. Pada sistem kerja kincir air, tidak semua energi yang dihasilkan oleh air dapat digunakan seluruhnya untuk menggerakkan sebuah kincir. Umumnya turbin air sangat baik untuk digunakan di daerah yang datar yang memiliki aliran sungai seperti aliran irigasi yang banyak kita jumpai di daerah pedesaan sampai saat ini kincir air makin banyak digunakan di daerah daerah DOI: 10.22236/teknoka.v5i.330 
yang memiliki sumber daya air yang baik. Namun banyak dari bentuk kincir air yang ditemukan tidak mempertimbangkan bentuk dasar aliran sungai apakah berpengaruh terhadap debit air dan efisiensi kincir. Oleh karna itu akan divisualisasikan aliran air dengan membuat sudut jumping pada dasar aliran air dengan membuat rekayasa aliran dengan di tambahkan zat berwarna untuk melihat pergerakan air yang terjadi saat melewati sudut jumping. Hal inilah yang menyebabkan perlunya penelitian untuk mengungkap seberapa pengaruhnya sudut jumping terhadap aliran air, Sehingga dapat diterangkan mengapa dengan membuat sudut jumping dasar kanal dengan sudut kemiringan berpengaruh terhadap daya dan efisiensi air. Perumusan masalah pada penelitian ini adalah seberapa besar pengaruh sudut jumping terhadap daya dan efisiensi air.

\section{LANDASAN TEORI}

\subsection{Fluida}

Fluida adalah suatu zat yang mengalami perubahan-perubahan bentuk secara continue/terusmenerus bila terkena tekanan/gaya geser walaupun hanya sedikit atau biasa juga disebut suatu zat yang mengalir, kata fluida mencakup zat cair, gas, air, dan udara karena zat-zat ini dapat mengalir. Karena sifatnya yang dapat mengalir dari satu tempat ke tempat yang lain semua zat cair itu dapat di kelompokan ke dalam fluida [2]. Sebaliknya batu dan benda-benda keras (seluruh zat-zat padat tidak dapat dikategorikan sebagai fluida karena zat-zat tersebut tidak bisa mengalir secara continue) di dalam suatu fluida terdapat gugusan yang tersusun di dalam suatu fluida atas molekul-molekul dengan jarak pisah yang cukup besar untuk gas dan jarak pisah yang cukup kecil untuk zat cair. Tidak dapat terikat pada suatu sisi molekul-molekul tersebut, melainkan saling bergerak bebas zat-zat tersebut terhadap satu dengan yang lainnya.

\subsubsection{Karakteristik Aliran}

Pada dasarnya aliran fluida dapat dibedakan dengan aliran dalam saluran, yaitu aliran yang dibatasi oleh permukaan-permukaan keras dan aliran sekitar benda, aliran fluida dapat diketegorikan sebagai berikut:

\section{Aliran Laminar}

Aliran laminar mempunyai gaya kekentalan (viscosity) yang relatif sangat besar di bandingkan dengan gaya inersia sehingga prilaku aliran berpengaruh terhadap kekentalan. Aliran ini bergerak dalam lamina-lamina dengan satu lapisan. Butir-butir air bergerak secara teratur atau lurus.

\section{Aliran Turbulen}

Apabila aliran dalam saluran terbuka kekentalannya relatif lemah dibandingkan gaya inersia maka itu dapat di katakan aliran turbulen. Di dalam lintasan butir - butir air ini bergerak tidak teratur, tidak tetap, tidak lancar, walaupun pergerakan air tetap maju secara keseluruhan. Aliran turbulen terlihat bergoncang dan sangat beda dengan aliran laminar. Dasarnya jika aliran air yang bergerak melaju terdapat partikel-partikel (butir-butir air) gerakannya berlawanan dengan arah pergerakan air maka itu dinamakan aliran turbulen.

\section{Aliran Transisi}

Aliran transisi adalah aliran peralihan dari laminar ke aliran turbulen. Aliran laminar, transisi atau turbulen sangat berbeda dilihat dari bilangan Reynolds. Menurut Osborne Reynolds, kecepatan aliran dikategorikan:

a) Aliran laminar, dengan nilai $\operatorname{Re}<2300$

b) Aliran turbulen, dengan nilai $\operatorname{Re}>4000$

c) Aliran transisi, dengan nilai Re diantara 2300 dan 4000 (bilangan Reynolds kritis)

\section{Aliran tetap dan tidak tetap}

Aliran tetap terbentuk apabila debit kedalaman dan kecepatan rata-rata pada setiap penampang aliran tidak berubah menurut waktu. Sedangkan aliran tidak tetap timbul apabila debit, kedalaman dan kecepatan rata rata pada setiap penampang aliran berubah menurut waktu.

\subsubsection{Aliran yang melewati bluff body trapezium}

Aliran fluida akan mecari kesetimbangan baru jika pergerakannya terhalang oleh suatu benda akan mengalami lapisan batas, separasi pemisah,sagnasi dan wake di belakang trapesium. Salah satu parameter yang menggambarkan pola aliran tersebut adalah angka Reynold (Re). Semakin bertambahnya nilai $(\mathrm{Re})$, pola aliran menjadi tidak stabil hal inilah yang menyebabkan terjadinya vortex sheldding. Aliran inkompresibel melintasi trapesium dapat di lihat gambar 1. 


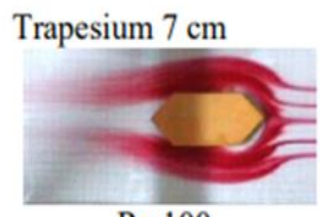

Re 100
$\operatorname{Re} 100$

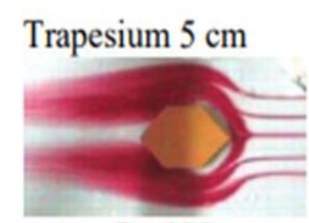

Gambar 1 Kualitatif aliran pada suatu trapesium [4]

Pada gambar di atas dapat dilihat panjang jarak sparasi antara gambar sebelah kiri dan kanan sangat berbeda karna perbedaan benda uji dan semakin panjang benda uji semakin panjang juga lebar wake. Hal ini membuktikan bahwa pola alira masih dalam kondisi laminar [4]. Salah satu parameter yang menggambarkan pola aliran tersebut adalah Reynolds Number (Re). Angka Re memiliki pola aliran yang berbeda-beda [3]. Pola aliran fluida tersebut diklasifikasikan pada Gambar 2.

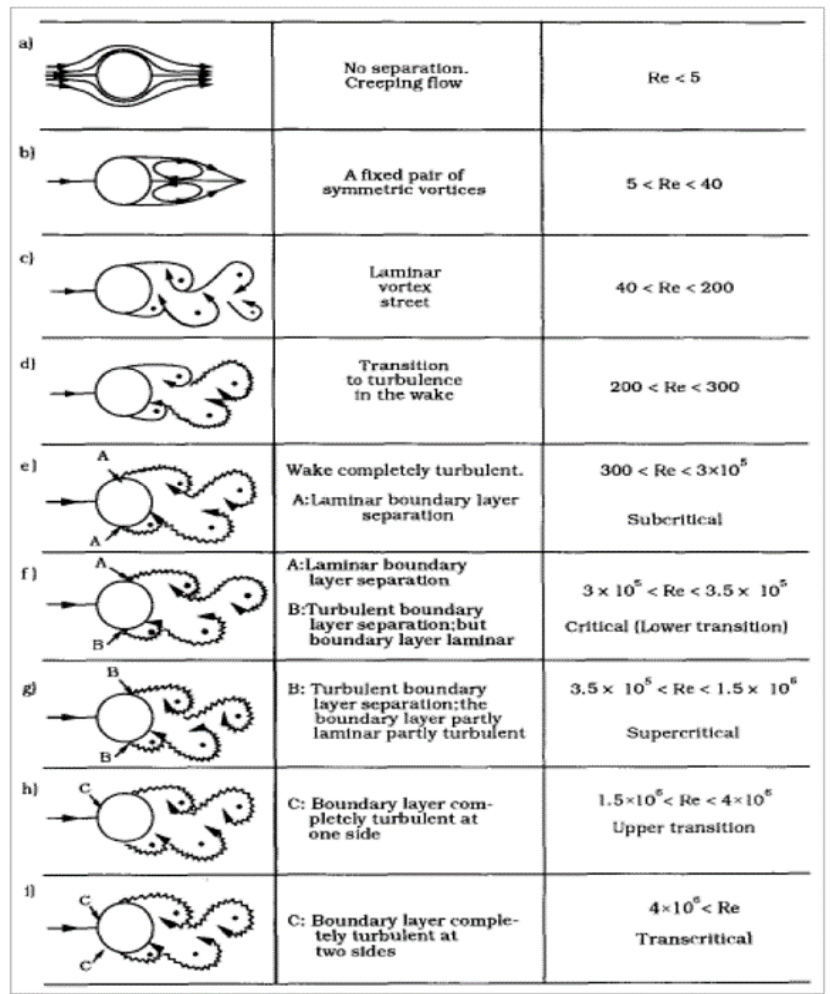

Gambar 2 Pola aliran fluida di sekitar silinder pada aliran steady [6]

Bilangan Reynold menyatakan perbandingan dari efek inersia terhadap efek viskos, dapat didefinisikan dengan:

$$
R e=\frac{\rho \cdot d \cdot \gamma}{\mu}
$$

\section{METODOLOGI PENELITIAN}

\subsection{Diagram alir Penelitian}

Mengidentifikasi masalah aliran yang terjadi pada saluran terbuka dengan membuat sudut jumping dan menambahkan zat berwarna untuk melihat pergerakan yang terjadi pada fluida. Studi pustaka dilakukan untuk mencari solusi yang lebih baik untuk metode visualisasi. Referensi dapat bersumber dari buku tes, jurnal dan lain lain. Kemudian dikembangkan lebih lanjut.

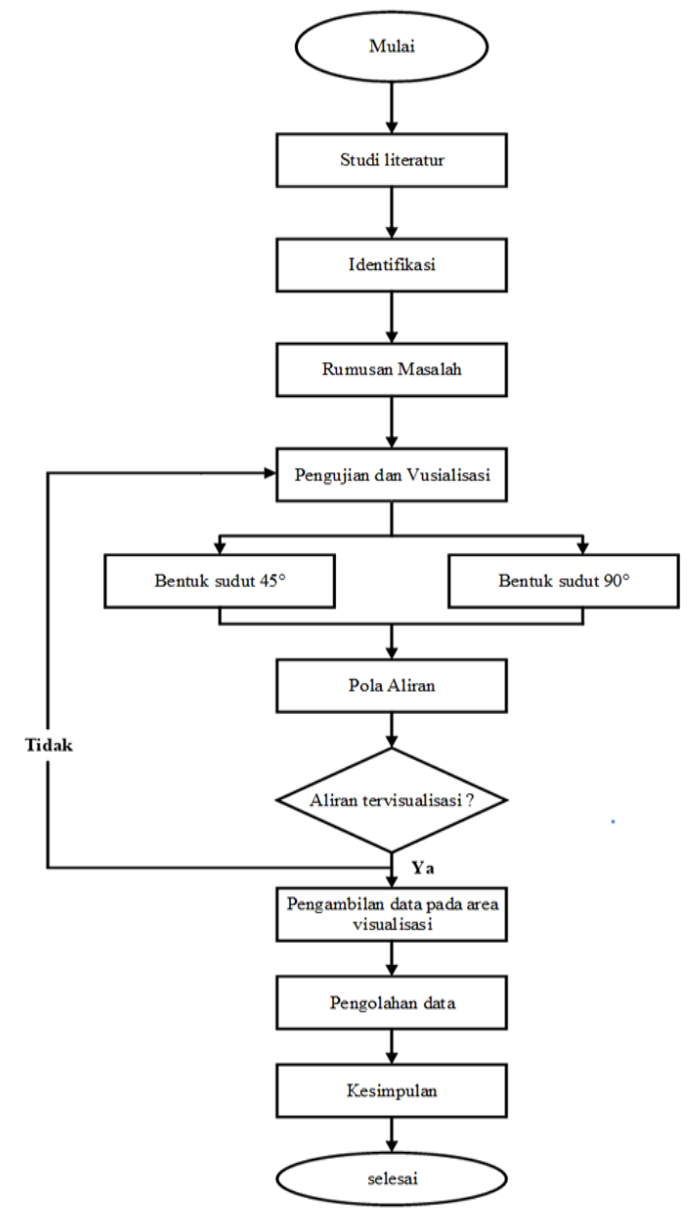

Gambar 3 Diagram Alir Penelitian

Hasil pada studi literatur yang didapat adalah metode untuk memvisualisasi aliran, bentuk dan ukuran alat visualisasi. Setelah mendapatkan ukuran dan bentuk maka dilakukan pembuatan rekayasa saluran air dan perakitan alat penunjang seperti pipa peralon, bak penampungan, pompa, talang air dan valve. Alat visualisasi yang sudah dirancang dilakukan percobaan sirkulasi air dari bak penampung yang di sirkulasikan oleh pompa menuju talang air untuk melihat apakah ada kebocoran yang terjadi atau tidak baru dilanjutkan dengan proses pengambilan data dengan merekam fonomena yang terjadi pada alirain Seminar Nasional TEKNOKA ke - 5, Vol. 5, 2020 ISSN No. 2502-8782 
air. Data yang didapat dari hasil pengujian diolah dengan cara merubah video menjadi foto untuk melihat bentuk aliran. Setelah melakukan pengolahan data dengan melihat pergerakan aliran air, jika data tidak dapat dianalisa maka perlu pengambilan data dan pengolahan ulang. Analisis dilakukan untuk menjawab fenomena yang terjadi selama pengujian kemudian dijelaskan pada simpulan.

\subsection{Alat dan Bahan}

\subsubsection{Alat}

Penelitian yang dilakukan menggunakan alat-alat sebagai berikut:

Tabel 1 Alat

\begin{tabular}{|c|c|}
\hline Nama & Fungsi \\
\hline Tabung pipet & Meneteskan zat pewarna \\
\hline Pompa air & Memompa air \\
\hline Tangki Penampung & Menyimpan air \\
\hline Selang Spiral 3 inch & Media aliran \\
\hline Stopwatch & Menghitung waktu \\
\hline Selang infus & Menginfus pewarna \\
\hline Lampu LED & penerangn \\
\hline
\end{tabular}

\subsubsection{Bahan}

Bahan-bahan penunjang dalam penelitian ini sebagai berikut:

\section{Tabel 2 Bahan}

\begin{tabular}{|c|c|}
\hline Nama & Fungsi \\
\hline Talang air 3 meter & Aliran air \\
\hline akrilik & Sudut jumping \\
\hline Pipa pvc $1 / 5$ inc & Mengalirkan air \\
\hline Pewarna makanan & Melihat aliran air \\
\hline
\end{tabular}

\subsection{Prosedur Penelitian}

Prosedur penelitian yang dilakukan sebagai berikut:

1. Pembuatan saluran air.

2. Membuat in dan out air pada saluran.
3. Perakitan sistem visualisasi.

a. Menaruh saluran air diatas meja.

b. Memasangan valve pada pembuangan air di saluran air.

c. Penempatan bak penampung air dibawah valve pembuangan air.

d. Memasang pompa pada bak penampungan.

e. Memasang pipa dari pompa menuju saluran air.

f. Memasang akrilik pada dinding saluran.

g. Memasang sudut jumping pada saluran.

h. Memasang lampu led.

i. Penempatan tripod handphone sebagai alat bantu rekam.

4. Pengisian air pada bak penampungan.

5. Melakukan tes kebocoran dengan cara menjalankan sistem visualisasi.

6. Pengamatan visualisasi dengan menambah zat pewarna.

7. Pengambilan data.

8. Pengolahan data dengan cara mengubah potongan video menjadi gambar.

9. Menganalisa gambar dengan gambar terbaik.

\subsection{Desain Penelitian}

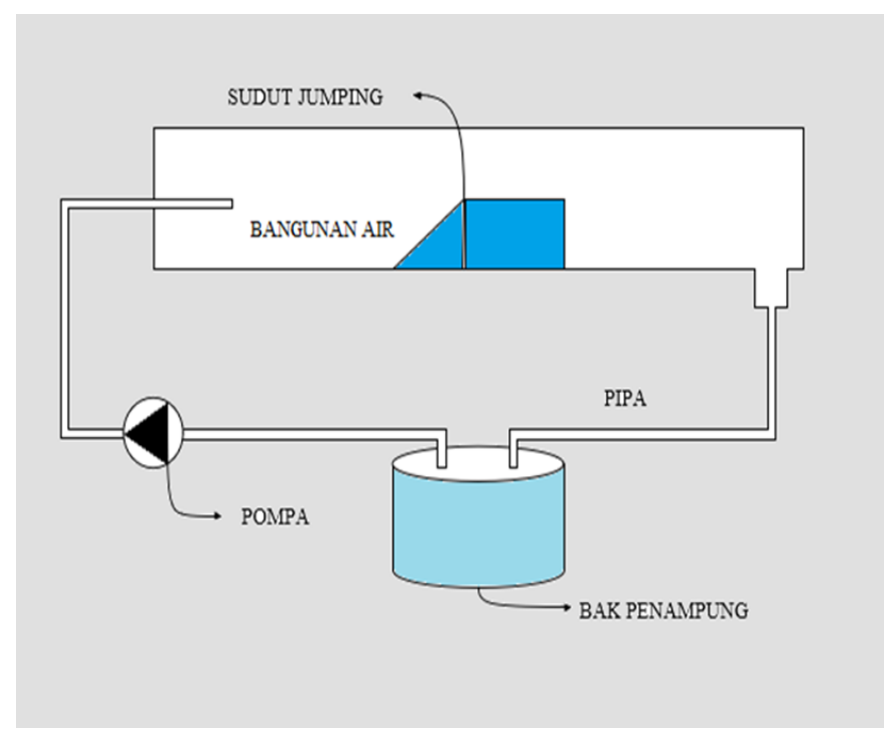

Gambar 4 Sistem pengujian

Pada Gambar 4 menunjukkan sistem sirkulasi air dari bak penampung menuju talang air melalui pipa yang dibantu dengan pompa air kemudian Kembali ke bak penampung. Bentuk bangunan air memiliki geometri sebagai berikut: 


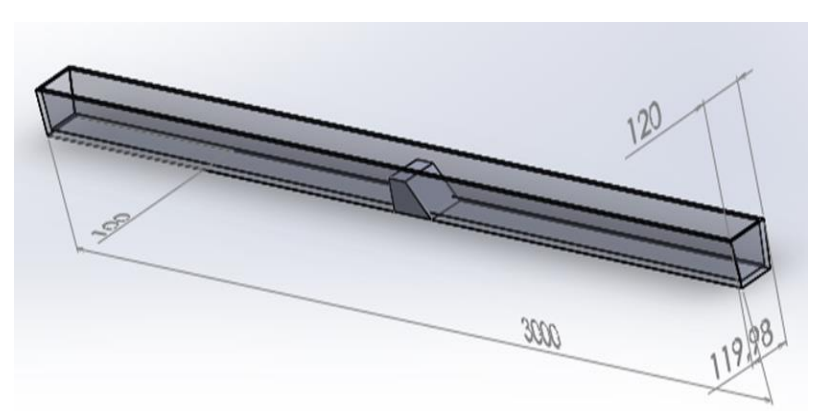

Gambar 5 Geometri saluran air (satuan pada gambar mm)

Air dipompa dari bak penampung dan mengalir melalui saluran air melawati sudut jumping dan menuju lubang pembuangan dan kembali ke bak penampungan air.

\subsection{Teknik Pengumpulan Data}

Metode pengambilan data pada penelitian ini dilakukan dengan cara merekam fenomena yang terjadi pada saat aliran melewati sudut jumping dengan menambahkan zat berwarna dengan menggunakan kamera.

\subsection{Teknik Pengolahan Data}

Pengolahan data pada penelitian ini dilakukan dengan cara merubah format video menjadi sebuah gambar menggunakan software Video to JPG Converter agar dapat disimulasikan dan dianalisa, menganalisa pergerakan partikel pada setiap gambar.

\subsection{Tempat dan Waktu Penelitian}

Penelitian ini dilaksanakan pada bulan februari sampai dengan bulan agsutus 2020 dan dilaksanakan di Kampus Fakultas Teknik Universitas Muhammadiyah Prof. DR. HAMKA.

\section{HASIL DAN PEMBAHASAN}

\subsection{Hasil Penelitian}

Parmeter yang mempengaruhi dari penelitian ini adalah sudut jumping dan Reynold number $(\mathrm{Re})$.

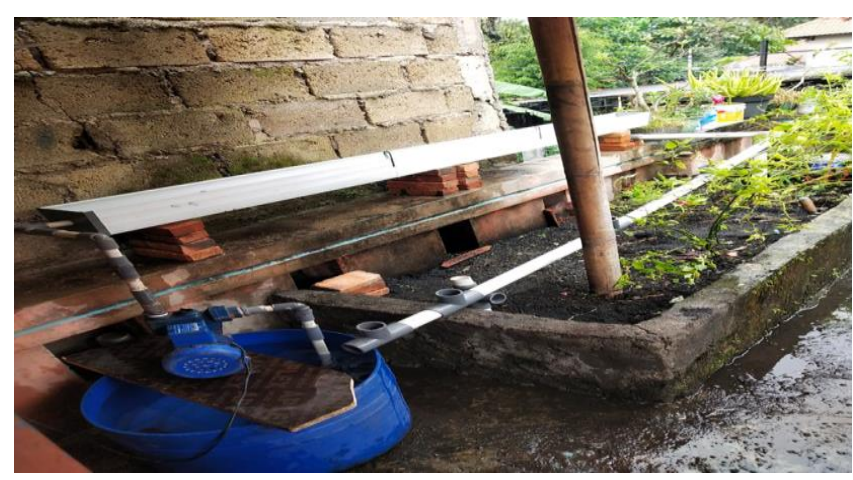

Gambar 6 Alat Pengujian
Cara kerja alat pengujian ini air yang berada dalam bak penampung di sedot oleh pompa dan di alirakan ke talang air dan keluar melalui saluran pembuangan dan di alirkan Kembali ke bak penampungan. Pada talang air diberikan sudut jumping umtuk melihat pengaruh yang terjadi saat air melewati sudut jumping dan pada bagian samping talang air di buat transparan untuk memvisualisasikan pergerakan air yang terjadi dengan memberikan zat pewarna menggunakan tabung pipet. Pada bagian talang di buat saluran pembuangan sesuai dengan air yang masuk ke dalam talang air untuk menjaga ketinggian air dalam saluran air.

\subsubsection{Pengukuran Volume Air}

Pengukuran volume air yang digunakan pada penelitian ini di hitung dari dimensi talang air dan ketinggian air didalam saluran air. Hasil dari pengukuran tinggi air di dalam saluran air memiliki ketinggian $6 \mathrm{~cm}(T)$, dengan panjang saluran $200 \mathrm{~cm}$ (P) dan lebar $12 \mathrm{~cm}$ (L) maka volume talang air tersebut adalah 14,400,000 atau 14.

\subsubsection{Pengukuran Debit Aliran}

Pengukuran aliran air di dalam sistem visualisasi menggunakan rumus perhitungan dengan mencari luas penampang, kecepatan aliran, dan viskositas air. Hasil dari perhitungan menggunakan rumus didapati debit air sebesar dengan nilai $\mathrm{Re}=46650$ dan $\mathrm{Re}=57416$ karena memakai dua kecepatan aliran yang berbeda.

\subsubsection{Fluida}

Fluida yang digunakan untuk visualisasi menggunakan penambahan zat berwarna kedalam air dengan menggunakan pipet kaca dengan dua varian zat berwarna yaitu berwarna merah dan kuning. penambahan zat berwarna sebanyak $2 \mathrm{ml}$ ke dalam aliran air.

\subsection{Pembahasan}

Pengujian pada aliran air yang melewati sudut jumping dengan kemiringan $45^{\circ}$ dan $90^{\circ}$ menunjukan bahwa aliran air bergerak turbulen dapat di lihat dengan menggunakan perhitungan nilai $(\mathrm{Re})$ sebagai berikut.
$\mathrm{v}$, kecpatan aliran $=1,30 \mathrm{~m} / \mathrm{s}$
$\mathrm{D}$, luas penampang $=300 \mathrm{~mm}=0,3 \mathrm{~m}$

Kekentalan kinematic, v:

$$
\mathrm{V} \text { air } 28^{\circ} \mathrm{C} \quad=8,36 \times 10^{-6}
$$


$R e=\frac{v d}{v} R e=\frac{1,30 \times 0,3}{8,36 \times 10^{-6}}=46650$

$\mathrm{v}$, kecpatan aliran $=1,60 \mathrm{~m} / \mathrm{s}$

$\mathrm{D}$, luas penampang $=300 \mathrm{~mm}=0,3 \mathrm{~m}$

Kekentalan kinematik, v:

$\mathrm{V}$ air $28^{\circ} \mathrm{C} \quad=8,36 \times 10^{-6}$

$R e=\frac{v d}{v} R e=\frac{1,60 \times 0,3}{8,36 \times 10^{-6}}=57416$

Ada dua perbandingan kecepatan aliran pada pengujian ini dengan nilai $\mathrm{Re}=46650$ dan $\mathrm{Re}=$ 57416. Setelah di beri zat berwarna hasil dapat dilihat secara langsung sebelum aliran air melewati sudut jumping $45^{\circ}$ dan $90^{\circ}$ dapat dilihat pada gambar 5 .

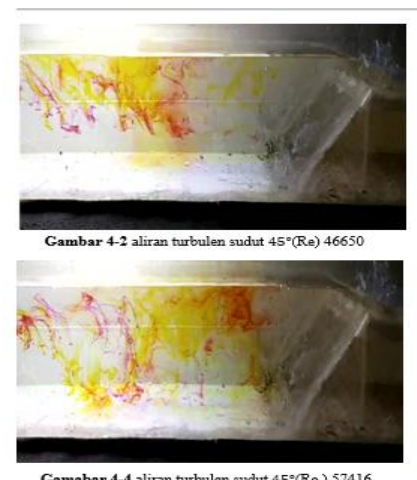

Gambar 7 Pengolahan data menggunakan software free video to jpg converter untuk menganalisa pergerakan fluida yang melewati sudut jumping

\subsubsection{Perbandingan (Re) dan sudut jumping}

Perbandingan yang dibuat pada penelitian ini di lihat dari (Re) pada aliran dan kemiringan sudut jumping pada saluran. Hal ini bertujuan untuk melihat pergerakan fluida disetiap perbandingan kemiringan sudut dan nilai re pada aliran, hasil dapat di lihat pada gambar 6 .

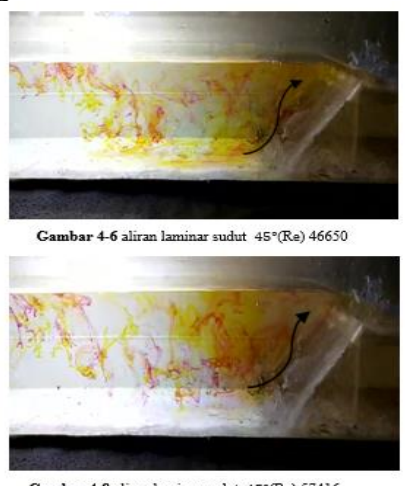

Gambar 4-8 aliran laminar sudut $45^{\circ}\left(\mathrm{Re}_{e}\right) 57416$

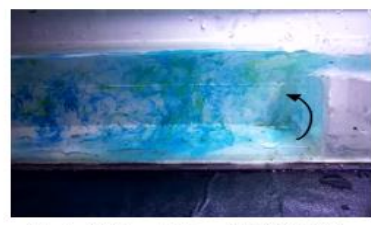

Gambar 4-7 aliran turbulen sudut $90^{\circ}(\mathrm{Re}) 46650$

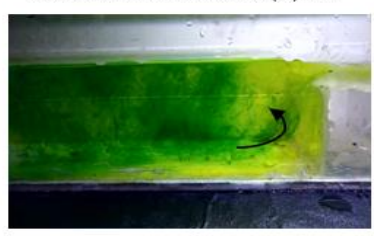

Gambar 4-9 aliran turbulen sudut $90^{\circ}(\mathrm{Re}) 57416$

Gambar 8 Hasil
Copyright (C) 2020 FT-UHAMKA. - All rights reserved DOI: 10.22236/teknoka.v5i.330

\subsection{Hasil Analisis}

Dari hasil analisis bentuk aliran di atas pada gambar 4-6 pergerakan aliran berbentuk turbulen hanya saja pergerakan aliran lebih smooth sedikit di banding dengan gambar 4-8 karena memang menggunakan kecepatan aliran yang berbeda namun pada saat aliran akan melewati sudut jumping kedua pergerakan aliran di atas berubah menjadi laminar karena bentuk sudut $45^{\circ}$ ini tidak membuat aliran yang melewati sudut ini berhenti dan berbalik menabrak dinding sudut jumping justru bentuk sudut jumping $45^{\circ}$ membuat aliran air menjadi terpusat ke satu titik. Beda hal nya dengan pengujian yang dapat dilihat pada gambar 4-7 dan 4-8 pergerakan air yang semulanya sudah turbulen tidak bisa bergerak laminar di karenakan bentuk sudut pada pengujian ini menggunakan bentuk sudut $90^{\circ}$. Jadi ketika aliran melewati sudut $90^{\circ}$ ini aliran akan tertahan karena bentuknya yang tidak bisa memusatkan air. Hasilnya aliran pada pengujian pada gambar 4-7 dan gambar 4-8 yaitu aliran tertahan di bawah dan sedikit berbalik membentuk aliran turbulen.

Bentuk sudut jumping ini sangat berpengaruh terhadap pergerakan dan efisiensi air. Seperti pada prototipe jumping water microhydro dengan membuat sudut jumping dengan berbagai macam kemiringan $10^{\circ}, 20^{\circ}, 30^{\circ}, 40^{\circ}$ dan $50^{\circ}$ [7]. Setiap perbandingan sudut kemiringan jumping water berpengaruh terhadap putaran kincir dengan menggunakan breastshot system water wheel sistem jenis ini sangat baik untuk meningkatkan kinerja air pada putaran kincir air. Dari data yang didapat pada lima perbedaan kemiringan sudut jumping dengan melihat posisi antara sudut jumping dengan kincir air kita akan melihat sudut jatuh air dari air terjun tertinggi disinilah perbandingan akan terlihat. Dengan mengukur dan menentukan jarak antara bilah kincir air dengan jatuhnya air yang akan mempengaruhi pergantian bilah kincir air. Dari perbandingan rata rata yang di dapat putaran kincir akan meningkat dan juga daya yang di hasilkan akan jauh lebih besar sesuai dengan ketinggian sudut jumping water dan juga jarak antara bilah angin dan jumping water.

\section{SIMPULAN}

\subsection{Simpulan}

Simpulan yang dapat diambil dari penelitian ini adalah: 
1. Bentuk sudut jumping sangat mempengaruhi aliran air yang akan melewati sudut jumping, perbedan derajat kemiringan pada sudut jumping akan menentukan perubahan pola aliran yang mengakibatkan air bergerak turbulen atau laminar.

2. Alat visualisasi dengan menggunakan zat berwarna sebagai media untuk melihat pola aliran dengan bantuan tabung pipet sebagai alat untuk meneteskan zat berwarna ke dalam aliran air tidak bisa dilakukan dengan kecepatan aliran yang sangat cepat karena zat berwarna tidak akan mengikuti pola aliran yang sesungguhnya dan akan cepat hilang karena terlalu derasnya kecepatan aliran.

\subsection{Saran}

Ada beberapa saran pada penelitan selanjutnya, yaitu:

1. Membuat alat tetes zat pewarna kedalam aliran air dengan alat yang lebih baik, agar aliran tervisualisasi dengan baik.

2. Membuat rekayasa aliran air dengan bentuk yang lebih besar, agar pola aliran terlihat lebih jelas.

\section{KEPUSTAKAAN}

[1] (Prasetyo et al., 2017) Prasetyo, A., Mesin, J. T., Sebelas, U., \& Surakarta, M. (2017). Unjuk Kerja Turbin Propeller. III, 0-3

[2] Abidin, K., \& Wagiani, S. (2013). Studi Analisis Perbandingan Kecepatanaliran Air Melalui. Dinamika, 04(1), 62-78.

[3] Bagas Pumbarino. (2017). fluida pada dua silinder dengan helical gaya eksitasi vortex shedding untuk konfigurasi side by side.

[4] Finahari, N., \& Widyagama, U. (2018).studi ekperimental visualisasi pola aliran dua dimensi di. August.

[5] Mattingly, G. E. (1966). Hydrogen Bubble Flow Visualization Technique. January, 116.

[6] Sumer, B. M., \& Fredsøe, J. (2006). Hydrodynamics around cylindrical strucures (Vol. 26).

[7] Syafriyudin, M., Firman, B., \& W, P. B. (2017). Jumping Water Method on Microhydro Power Plant for Water Channel. 102(Ictvt), 132-137. https://doi.org/10.2991/ictvt-17.2017.24 